\title{
Study on the Strategy of Ancient Village Development in the New Era
}

\section{Tong Fenglian}

\author{
Humanities and Education College, Wuhan Guanggu Vocational College, Wuhan, Hubei, 430073
}

Keywords: ancient village; culture; new era; development; innovation

\begin{abstract}
: ancient village as the crystallization of human history civilization, has a strong cultural heritage, in the years of change, has become a living fossil in general. This paper mainly introduces the background of the development and innovation of ancient villages in the new era, and further analyzes the obstacles to the development and innovation of ancient villages, as well as the working principle of the development and innovation of ancient villages. In the end of the article, the author puts forward the optimization strategy of the development and innovation of ancient villages under the new era background.
\end{abstract}

\section{The ancient village development background, a new era of innovation under the background}

The ancient village as a special landscape, it is the history of the national connotation. With its unique traditional elements, it reflects the evolution process of different periods, regions and economic development. It can be said that to understand a nation, ancient villages are the elements that can not be ignored. Ancient village is not only the place of historical and cultural heritage, but also contains a large number of intangible cultural heritage. For example, traditional culture, national festivals and national skills and so on, is the combination of material cultural heritage and intangible cultural heritage. Ancient villages reflect the cultural connotation of specific areas of our country, heritage and development of ancient villages, is to strengthen our cultural foundation and history.

Traditional villages have a long history, Chinese traditional villages are precipitated in the history of the Chinese nation, but also a "mixed together", "small settlements" this basic pattern of social development of the complex. Chinese traditional culture originated from the farming civilization, the Chinese nation in the long history, in the vast land gathered together and lived, formed by the blood relationship of the village, with blood source, regional characteristics. The village legend, Genealogy Family, ancestral culture and folk festivals, rich, deep history and culture. From another perspective, the ancient village is a living fossil of the local culture, is also a museum. The ancient village retains a lot of China traditional culture and even the heritage of thousands of years of customs. Protection and development of ancient village culture, compared with the understanding of the historical data of ancient antiquities, has more fresh activity, which is derived from our national empirical. Protection and inheritance of these traditional villages, not only to protect the old, old houses, but also in the inheritance and development of our Chinese nation roots [1].

At present, the ancient village of this word has not been clearly defined. It can be understood that when a village has a very precious material and spiritual heritage, which has been inherited and preserved, and has obvious regional characteristics, we can identify it as an ancient village. From another point of view, the ancient village is a village with certain characteristics in the whole environment and traditional culture after the vicissitudes of history and the times. The core of ancient villages should be villages with traditional meanings, carrying intangible cultural heritage, with traditional spatial layout and environmental factors [2].

The inheritance and innovation, the need for protection and development. From the further understanding of the ancient villages in the identification, protection, protection, repair and regeneration. Could also be extended to the preservation and restoration of historic towns, so that residents living more harmonious. From the dynamic point of certain point of view, it contains a lot 
of protection.

In the planning area of the ancient village, and update the "city" two words are complementary. Especially after World War II, "urban renewal" prevailed in Europe and America, and was applied to urban problems. Its core purpose is to coordinate the relationship between the urban development and city coordinated. Mainly includes the social economy and technology in the field of Engineering problems. To the world stage, city renewal is has a certain historical value and cultural city. With the rising awareness of the protection of famous cities and ancient villages, renovation, renovation, renovation and maintenance have been widely used in the process of development and innovation of ancient villages.

\section{Problems in the development of ancient villages under the background of the new era}

Due to the lack of awareness of the protection of ancient villages, ancient villages and people's perennial migrant workers, the problem of aging gradually increased, and gradually to the empty nest village trend, inheritance and development of ancient villages if things go on like this, will become a serious problem. Coupled with the acceleration of the urbanization construction and the construction of the beautiful countryside for instant success, some "image project" is exposed to public view, most of the damage development construction continues, this is because of the lack of awareness to the protection of the ancient village [3].

The old house is not demolished, new level down policy still exist some loopholes, there are many careless machines in rural planning, no construction orders and scientific research, which leads to the villagers can not effectively improve the living conditions of village layout style self destructive construction intensified. In addition, most of the historical and cultural villages are re declared, but do not attach importance to the protection, attach great importance to the development of tourism resources, but do not pay attention to the protection of historical and cultural. Excessive commercial exploitation will lead to the destruction of ancient villages by tourism development. Ancient villages have long been regarded as "shrinking management", and the policy is obviously lagging behind. In the new rural construction, the lack of investment subsidies for ancient villages, the construction of rural local building property rights division is not clear, which all bring some problems to the protection of ancient villages.

The ancient village has a vernacular architecture, the development characteristics of large scale, based on these conditions, the maintenance of the process, must have higher costs, but the financial investment is generally inadequate, special funds and the lack of talents, which will restrict the development of the new era of innovation under the background of the ancient village [4].

\section{The development of ancient village under the background of new era, three innovation principles}

The constant change of urban structure brings more opportunities for the development of ancient villages, which makes it face the threat of being gradually engulfed by the urbanization process. So, people need to further examine the ancient village unique resources, explore the development path of the beginning of the ancient village and city integration, to develop appropriate protection strategies, under the background of new period, realize the optimization development of ancient villages fall.

In the development of ancient villages, innovation, should fully respect the historical and cultural heritage, properly preserve the corrosion and wear parts, not because of some damage completely transformed, in fact, ancient villages have their own style, with a certain sense of the old is the best in history, of course, should also set up some measures two, to avoid damage. The ancient village bears the responsibility to help modern people to understand the past of the task, so the maintenance of the ancient villages, is to respect the folk custom, a manifestation of respect for culture, not because of excessive repair makes them lose the intrinsic value of the culture itself.

The charm of ancient villages lies in the unity of form and spirit, that is, the unity of form and meaning, so it embodies not only the external form, but also the intrinsic spirit contained in it. 
Focus on the combination of form and meaning, can let the ancient village more flavor. In the renovation of ancient villages, we should give full consideration to the overall style of the ancient villages and the charm of them, so that the repair part and culture, meaning want to combine.

To realize the innovation and perfection of the ancient village development, this is a whole concept, not only to protect the material heritage, but also to protect its ecological system and social life system. But for some ancient villages which have been developed, only paying attention to the cultural relics and ignoring the cultural connotation, it violates the overall principle of the ancient village development. In the renovation of ancient villages, we should combine its spatial layout and understand its causes, and continue to continue its style, pattern, and achieve the integration with the overall environment.

For those who live in ancient villages, they also hope to effectively improve their quality of life, in the process of ancient village development, can not fully protect ancient villages and ignore the idea of the villagers. Even to protect ancient villages, we should also keep pace with the times, in order to meet the needs of the villagers without destroying the original style of ancient villages, and further optimize their living conditions. Under the current social and economic background, the development of characteristic tourism in ancient villages is an effective means to realize economic recovery in a region. But the real negative impact on the ancient village tourism caused obviously. Tourists and operators will inevitably bring some interference to the villagers' lives. If we blindly change the values of the villagers, it will inevitably lead to the decline of ancient village culture. Therefore, the tourism development of ancient villages, should adhere to the principle of moderation and parallel scalability [5].

\section{The optimization strategy of ancient village development background for new period}

Governments at all levels should further strengthen the awareness of cultural consciousness, and protect ancient villages and urban and rural integration as an important development goal. It will be included in the policy assessment, the establishment of effective accountability system and ancient village protection team, to ensure that departments perform their duties, do a good job of protection, utilization and development of innovative work. The people's congresses and CPPCC should fully play the role of guidance and supervision and inspection. Experts check to strengthen the protection of ancient villages, effectively put forward regulations and policy suggestions. Media at all levels should give full play to the role of public opinion, and strive to create a whole society to protect the ancient village atmosphere. College Party school should actively set up administrative and cultural protection project, enhance the cultural consciousness of officials. Governments at county level and above should formulate scientific innovation plan according to the current situation of the development and innovation of ancient villages. The ancient village development of provincial housing department and bureau of cultural relics consent project. County level construction and cultural relics departments should implement the monitoring system, and timely grasp and predict the development and innovation of ancient villages.

The innovation of ancient villages should be further diversified and socialized, and the protection projects of ancient villages should be explored to realize diversified protection modes such as property right transfer, villagers' self protection and collective financing protection of villages. Encourage social organizations and individuals to adopt and claim to participate in the protection of ancient villages, thus speeding up the protection and utilization of ancient village vernacular architecture, to achieve more diversified development. The ancient village planning, according to the plan, the status of resources, scientific and reasonable arrangement of the region, in essence, should be combined with the rural local economy, culture, topography and other factors, so that these factors are coordinated, so that it can more effectively save manpower, follow-up work and financial resources. In the water on the ground, the rational allocation of resources, adhere to the plan, saving construction [6].

The development of ancient villages to achieve a combination of environmental remediation, as the basis for development. At the same time also should be combined with the tourism industry, cultural industry, it is easier to find development goals. We should not only carry forward the 
cultural and natural heritage of ancient villages, but also make rational exploitation and utilization of the projects to change the appearance of the ancient villages. Not only to the ancient village of Zheng Zhihao style, pattern and natural ecological environment, but also to strengthen infrastructure construction, improve the living conditions of villagers backward, to encourage the villagers to enjoy modern civilization, better use of Gu village round development of tourism and leisure and cultural and creative industries, to achieve protection and strengthen the development of a virtuous cycle of development, urge protection.

The protection and utilization of ancient villages, to adhere to the people-oriented policy. The development of ancient villages, to respect the wishes of the villagers, not to large demolition, can not let go of all residents migration. Always adhere to the living state protection of life and cultural continuity. The protection of ancient villages should be obtained by permission of the villagers. The rectification policy should be set up with villagers, protect the natural ecological environment of the village, maintain the relaxed and quiet life of the residents, and avoid interfering with the original living customs of the villagers. Mobilize the enthusiasm of the villagers, initiative, the introduction of policies to support the villagers, the use of vernacular architecture to further develop the farmhouse economy, agricultural tourism, so that the development of the results can benefit all villagers. In the process of development, more local cultural projects should be used to pass more ancient villages and customs to the society.

\section{Conclusion}

At present, the protection and development of ancient villages has been listed as one of China's key project planning. With the development of new socialist countryside, the ancient villages are faced with many challenges because they have no effective protection measures. In order to further avoid the erosion of the ecological features of ancient villages, it is urgent to strengthen the protection of ancient village cultural heritage and formulate new development policies.

\section{References}

[1] Kong Xiang, Zhuo Fang Yong1, Miao Chang Song. Tourism development situation on effect of culture protection of the ancient village -- Based on Hongcun, Chengkan, Xu village residents survey [J]. tropical geography, 2016,36 (02): 216-224.

[2] Shao Xiuying, Feng Weihong. Research on the coordinated development model of ancient village protection and poverty reduction based on Industrial Development -- Taking Shanxi Province as an example, [J]. economic research reference, 2015, (52): 35-40.

[3] Hong Xiafang. Thinking of tourism development of ancient villages in Jiangxi from the perspective of empowerment -- County as an example [J]. enterprise economy, 2012,31 (03): 141-144.

[4] Aryan Z, Holgate S T, Radzioch D, et al. A New Era of Targeting the Ancient Gatekeepers of the Immune System: Toll-Like Agonists in the Treatment of Allergic Rhinitis and Asthma[J]. International Archives of Allergy \& Immunology, 2014, 164(1):46.

[5] Lin L I. Research on the Documents of Chinese Ancient Literature in the New Era[J]. Fudan Journal, 2014.

[6] Hong-Zhen H U. Discussion on Library Ancient Book Reservation and Utilization in the New Era[J]. Journal of Library \& Information Sciences in Agriculture, 2009. 